\title{
Comparison between Glass and Stainless-Steel Vessels in Differential Scanning Calorimetry Estimation
}

\author{
Miyako Akiyoshi*, Ken Okada, Shu Usuba, Takehiro Matsunaga \\ Explosion Safety Research Group, Research Institute of Science for Safety and Sustainability, National Institute of Advanced \\ Industrial Science and Technology, Tsukuba, Japan \\ Email: *miya-akiyoshi@aist.go.jp
}

How to cite this paper: Akiyoshi, M., Okada, K., Usuba, S. and Matsunaga, T. (2017) Comparison between Glass and StainlessSteel Vessels in Differential Scanning Calorimetry Estimation. American Journal of Analytical Chemistry, 8, 19-34.

http://dx.doi.org/10.4236/ajac.2017.81002

Received: November 17, 2016

Accepted: January 1, 2017

Published: January 4, 2017

Copyright (๑) 2017 by authors and Scientific Research Publishing Inc. This work is licensed under the Creative Commons Attribution International License (CC BY 4.0).

http://creativecommons.org/licenses/by/4.0/

\begin{abstract}
Differential scanning calorimetry (DSC) provides easy screening for thermal hazard evaluation. Here, we investigate the difference between using glass and stainless-steel vessels on the DSC measurement of exothermic decomposition energy ( $\mathrm{Q}_{\mathrm{DSC}}$ ) for 41 chemical substances (containing nitro, halogen, peroxide, and sulfur groups, and hydrazine bonds). Two borosilicate glass vessels (capillary and ampule) and one stainless-steel vessel were used. All QDSC values obtained were investigated with reference to the permissible fluctuation range specified by the ASTM (American Society for Testing and Materials) international Both glass vessels produced very similar $Q_{D S C}$ values, despite different sample scales. The Q $\mathrm{DSC}$ values obtained with the glass vessels were generally roughly within the variation tolerance range of the stainless-steel vessel. Notable exceptions were halogen- or sulfur-containing compounds; these exhibited smaller $Q_{D S C}$ values with glass vessels in almost all cases. We will investigate whether certain structures in compounds react with stainless steel. The vessel material choice is crucial in evaluating the true reactivity of a substance.
\end{abstract}

\section{Keywords}

Differential Scanning Calorimetry, Glass Vessel, Stainless-Steel Vessel, Exothermic Decomposition Energy, United Nations Recommendations

\section{Introduction}

Differential scanning calorimetry (DSC) provides a quantitative evaluation of the calorific energy associated with a chemical or physical change in a chemical substance. As the explosiveness of a chemical substance is correlated with the calorific value of its exothermic decomposition energy, DSC has also been used 
as a hazard evaluation test. In fact, the United Nations recommends the use of DSC in transporting dangerous goods as a means of screening for chemicals that are considered an explosive according to Test Series 1 and/or Test Series 2 [1] [2]. However, both these tests are quite complex and require large amounts of material, which may not necessarily be available in the early development of a new compound. Therefore, since it is not always possible to apply these tests, the exothermic decomposition energy ( $\mathrm{Q}_{\mathrm{DSC}}$ ) of a chemical is used to indicate whether these tests are needed. This led to the creation of the Japanese Industrial Standard (JIS) "Measurement method of exothermic decomposition energy for estimation of explosivity," which was enacted in January 2013 (JIS K 4834) [3]. Furthermore, DSC measurement has been incorporated in the Fire Services Act of Japan as a suitable examination technique for judging whether a chemical substance can be defined as self-reactive. Although DSC provides a safe means of performing risk assessment of chemicals, with the convenience of only requiring very small amounts of material, the value obtained is known to be affected by, e.g., the sample vessel material/type, the heating rate, and the sample volume. Nevertheless, these effects have not been studied in detail; most researchers tend to use their own preferred vessel for thermal risk assessment. Judging from recent research trends, pressure vessels seem to be the most commonly used in studying the relationship between the thermal reactivity and explosiveness of a chemical substance [4] [5] [6] [7] [8]; however, chemicals have also been examined using an aluminum pan [9] [10] [11], alumina vessel [12], and glass capillary tube [13].

There is a pressing need to determine the influence that measurement conditions have on the thermal behavior of common substances in DSC. We have already reported that a gold-plated stainless-steel vessel, used widely for its inertness, has an influence on the thermal reaction [14]. Our present study focuses on comparing the variation in the measured exothermic decomposition energy when using stainless-steel and glass vessels for several chemical substances

\section{Experiment}

\subsection{Samples}

A total of 41 sample types were used in this investigation; all reagents were sourced from Wako Pure Chemical Industries, Ltd. The samples were chosen from substances having the characteristic structures listed in Table 1. We focused on substances that may react with stainless steel. There may be other materials that react with stainless steel, in addition to those listed here. For convenience, these reagents are hereafter referred to by their abbreviationslisted in $\mathrm{Ta}$ ble 1.

\subsection{Experiment}

Two types of glass vessels were used in this study: a borosilicate glass (Pyrex) capillary vessel (GC) and a Pyrex ampule (GA). The glass capillary vessel (GC) had an outside diameter of $1.7 \mathrm{~mm}$, an inside diameter of $1.4 \mathrm{~mm}$, and a length of 11 
Table 1. Samples.

\begin{tabular}{|c|c|c|c|}
\hline No. & & Material & Abbreviation \\
\hline 1 & \multirow{11}{*}{$\begin{array}{l}\text { A) Nitro } \\
\text { group-containing }\end{array}$} & 2,4-Dinitrotoluene & DNT \\
\hline 2 & & p-Nitrotoluene & pNT \\
\hline 3 & & 2,4,6-Trinitrophenol & TNP \\
\hline 4 & & 2,4-Dinitrophenol & DNP \\
\hline 5 & & 2-Amino-4,6-dinitrophenol & ANP \\
\hline 6 & & o-Nitrophenol & oNP \\
\hline 7 & & p-Nitrophnol & $\mathrm{pNP}$ \\
\hline 8 & & 3-Methyl-4-nitrophenol & MNP \\
\hline 9 & & 2,4-Dinitrobenzoicacid & $24 \mathrm{DNBA}$ \\
\hline 10 & & 3,5-Dinitrobenzoicacid & 35DNBA \\
\hline 11 & & 4-Nitro-1,2-phenylenediamine & NPD \\
\hline 12 & \multirow{10}{*}{$\begin{array}{l}\text { B) Hydrazine bonding } \\
\text { containing }\end{array}$} & 4-Nitrophnylhydrazine & $\mathrm{mCPBA}$ \\
\hline 13 & & 2-Nitrophenylhydrazine & CNBA \\
\hline 14 & & 1-Acetyl-2-phenylhydrazine & ACNP \\
\hline 15 & & 1-(Tert-Butoxycarbonyl)-2-phenylhydrazine & $\mathrm{BNP}$ \\
\hline 16 & & Anthraniloylhydrazine & $\mathrm{AH}$ \\
\hline 17 & & Maleic hydrazide & MH \\
\hline 18 & & Nicotinic hydrazide & $\mathrm{NtH}$ \\
\hline 19 & & 1,2-Diformylhydrazine & DFH \\
\hline 20 & & Azoxybenzene & AzoxyB \\
\hline 21 & & 4,4'-Azoxydianisole & AzoxyA \\
\hline 22 & \multirow{9}{*}{ C) Sulfer-containing } & Thiosemicarbazide & TSC \\
\hline 23 & & 4-Methyl-3-thiosemicarbazide & MTSC \\
\hline 24 & & 1-Phenyl-3-thiosemicarbazide & PTSC \\
\hline 25 & & Benzenesulfonyl hydrazide & $\mathrm{BSH}$ \\
\hline 26 & & m-Nitrobenzenesulfonic Acid Sodium Salt & mNBSNa \\
\hline 27 & & 2-Formylbenzenesulfonic acid sodium salt & FBS \\
\hline 28 & & 2-Hydrazinobenzothiazole & HBT \\
\hline 29 & & 2-n-Octyl-4-isothiazolin-3-one & OIT \\
\hline 30 & & Dithizone & $\mathrm{DtZ}$ \\
\hline 31 & \multirow{4}{*}{ D) Harogen-containing } & 3-Chloroperbenzoic Acid & $\mathrm{mCPBA}$ \\
\hline 32 & & 2-Chloro-5-nitrobenzoic acid & CNBA \\
\hline 33 & & 2-Amino-4-chloro-5-nirtrophenol & ACNP \\
\hline 34 & & 2-Bromo-2-nitropropane-1,3-diol & $\mathrm{BNP}$ \\
\hline 35 & \multirow{5}{*}{ E) Peroxide } & Tert-Butyl perbenzoate & TPBP \\
\hline 36 & & Benzoyl peroxide & $\mathrm{BPO}$ \\
\hline 37 & & Tert-Butyl peroxide & DTBP \\
\hline 38 & & Cumen hydroperoxide & CHP \\
\hline 39 & & Tert-Butyl hydroperoxide & TBH \\
\hline 40 & \multirow{2}{*}{ F) Misc. } & 1,4-Naphthoquinone & $\mathrm{NaQ}$ \\
\hline 41 & & 4-Picoline-N-oxide & $4 \mathrm{PNO}$ \\
\hline
\end{tabular}


$\mathrm{mm}$. After filling this vessel with $0.5-1 \mathrm{mg}$ of the sample, the upper part of the vessel (positioned about $11 \mathrm{~mm}$ from the bottom) was sealed using a burner, while the lower part was cooled by liquid nitrogen; the ratio of the vessel volume to the sample mass varied between 10 and $27 \mu \mathrm{l} / \mathrm{mg}$. The capillary was then inserted into an aluminum holder and set horizontally in a differential scanning calorimeter (EXSTAR DSC7020, manufactured by SII Nano Technology Inc.), as shown in Figure 1. The sample was then heated to $500^{\circ} \mathrm{C}$ at $5^{\circ} \mathrm{C} / \mathrm{min}$.

The glass ampule vessels (GA) had an inside diameter of $3.4 \mathrm{~mm}$, an outside diameter of $5 \mathrm{~mm}$, and a length of $20 \mathrm{~mm}$. These were filled with $10-20 \mathrm{mg}$ of sample, and then, sealed with a burner while cooling the opposite end with liquid nitrogen, giving a vessel volume to sample mass ratio of between 12 and 20 $\mu \mathrm{l} / \mathrm{mg}$. The ampules were then tested using a high-pressure DSC device manufactured by Palmetrics Co., Ltd., which was slightly modified to estimate the thermal behavior using a glass ampule. Finally, the ampules were inserted into an aluminum holder (Figure 2) and set in the high-pressure DSC device. Each sample was heated to $400^{\circ} \mathrm{C}$ at $2^{\circ} \mathrm{C} / \mathrm{min}$.

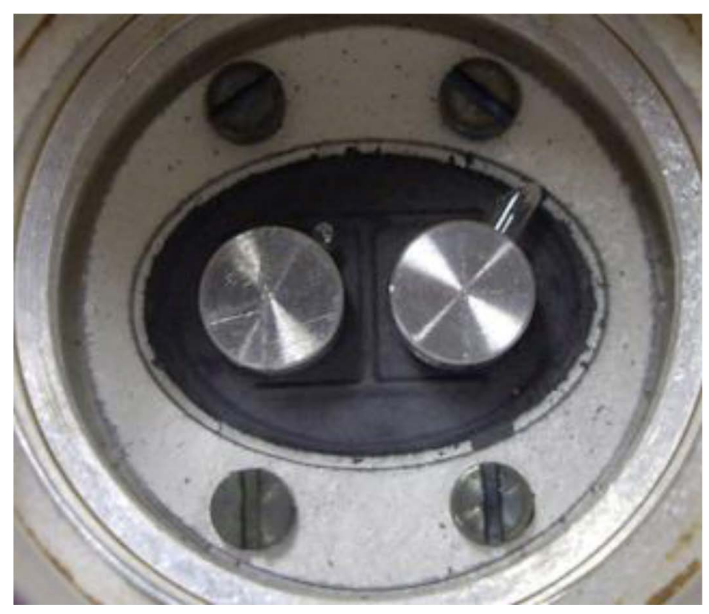

Figure 1. The glass capillary vessel that was inserted into an aluminum holder.

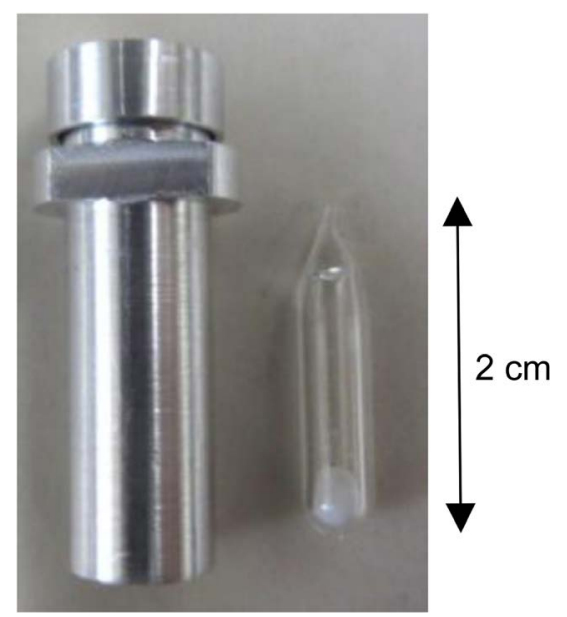

Figure 2. The glass ampule vessel. 
Evaluations with the high-pressure stainless-steel vessel (SS) were performed to compare with the results of the glass vessels. The stainless-steel vessel was manufactured by SII Nano Technology Inc. and the sample amount was about 1 $\mathrm{mg}$. The vessel volume to sample mass ratio was $15 \mu \mathrm{l} / \mathrm{mg}$. The measurements were performed while heating to $500^{\circ} \mathrm{C}$ at $5^{\circ} \mathrm{C} / \mathrm{min}$.

All devices were calibrated using $10 \mathrm{mg}$ of four to five types of a dedicated standard metal (biphenyl, In, Sn, $\mathrm{Pb}, \mathrm{Zn}$, and $\mathrm{Al}$ ) under each condition. The device condition was also confirmed by measuring these standard substances in the measurement mode. According to the ASTM (E537-07) [15] [16], QDSC data can be considered reliable if the standard deviation is within 3.5\%, and the reproducible standard deviation for a given sample is within $4.7 \%$. However, there is a problem if these values exceed 9.7\%. For each condition, the Q $_{\text {Dsc }}$ obtained for the standard material was in the permissible range of the fluctuation.

\section{Results and Discussion}

The QDSC values measured for the 41 chemical substances with each vessel type are plotted (Figure 3) [17]; the horizontal axis is consistent with the numbering used in Table 1. Two times of measurement was carried out in each sample. The reproducibility in the thermal behavior was recognized. The $\mathrm{Q}_{\mathrm{DSC}}$ obtained with the stainless-steel vessel is thus analyzed with respect to the permissible range of variation based on a report by the ASTM, indicated by the tolerance bars in Figure 3.

In several cases, the $\mathrm{Q}_{\mathrm{DSC}}$ values obtained for the glass capillary vessel (GC/GA) are not within the $\mathrm{Q}_{\mathrm{DSC}}$ tolerance range for the stainless-steel vessel. However, the $\mathrm{Q}_{\mathrm{DSC}}$ values for the melting points are within the variation tolerance range in all cases. The sample vessel materials appear to affect only the decomposition phenomena.

\subsection{Nitro Compounds}

As for nitro compounds, there is a tendency for the $\mathrm{Q}_{\mathrm{DSC}}$ value obtained in a glass vessel to be smaller than that obtained in a stainless-steel vessel in p-nitrotoluene and a mononitro compound. However, we cannot ignore the influence of a different factor on these substances. Figure 4 shows the effect of varying the amount of oNP relative to the volume of the glass capillary vessel (GC) on the QDSC values obtained. It is evident that varying the relative amount of oNP affects the peak shape, with a similar tendency being observed for the stainless-steel vessel. As the quantity of the sample increases, the peaks at around $290^{\circ} \mathrm{C}$ and $380^{\circ} \mathrm{C}$ become shoulders of the mainpeak and that at around $313^{\circ} \mathrm{C}$ increases in intensity. oNP is volatile at room temperature, which is attributed to the sublimation characteristics of the sample. Changing the amount of solid material should affect the ratio between the gas-phase reaction and the condensation-layer reaction. In the case of oNP, it is also confirmed that the peak shape changes according to the physical state of the sample in the vessel (fluffy or compressed), despite the quantity of the sample being identical. In addition to 

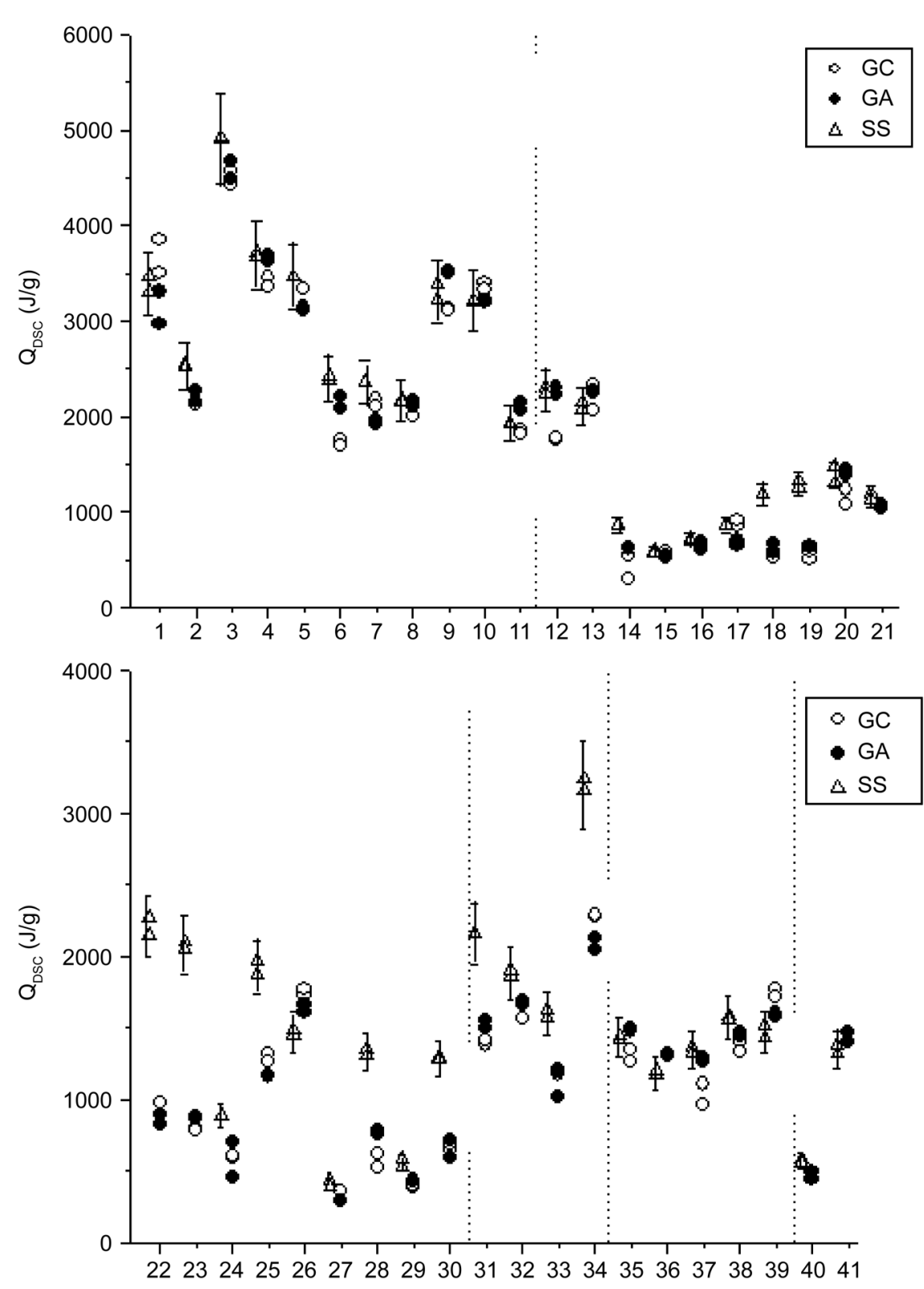

Figure 3. The QDSC values measured for the 41 chemical substances with each vessel type (GC, GA and SS).

chemical reactions, other factors can also influence the QDsc value, making the evaluation of the calorific value difficult. Microphotographs of the vessel surface taken after calorific evaluation in a stainless-steel vessel do not indicate surface modification. Figure 5 shows a DSC curve for a mixture of an oNP and a stainless-steel foil (SUS304, $1 \mathrm{~mm} \times 6 \mathrm{~mm} \times 0.01 \mathrm{~mm}$ ), where the amount of oNP is about $0.30 \mathrm{mg} / 10 \mu \mathrm{L}$. This is the smallest quantity of sample used to fill the vessel shown in Figure 4. Figure 6 shows a microscope photograph of a glass capillary vessel (GC) with added SUS304 foil before and after the measurement. The addition of the SUS foil results in a change in the peak shape; the peak at around $290^{\circ} \mathrm{C}$ increases in intensity and that at around $380^{\circ} \mathrm{C}$ decreases. It is also confirmed that the peak shape is affected by the sample quantity of oNP. It is not 


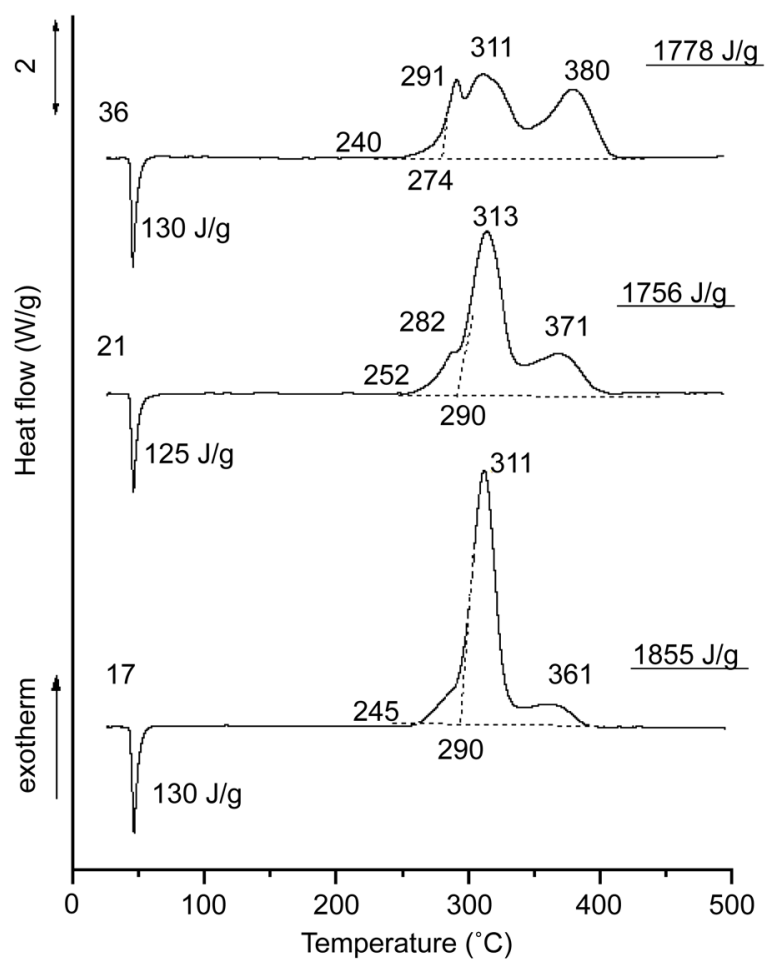

Figure 4. Influence of the sample amount on the DSC curve (sample: oNP, vessel: glass capillary).

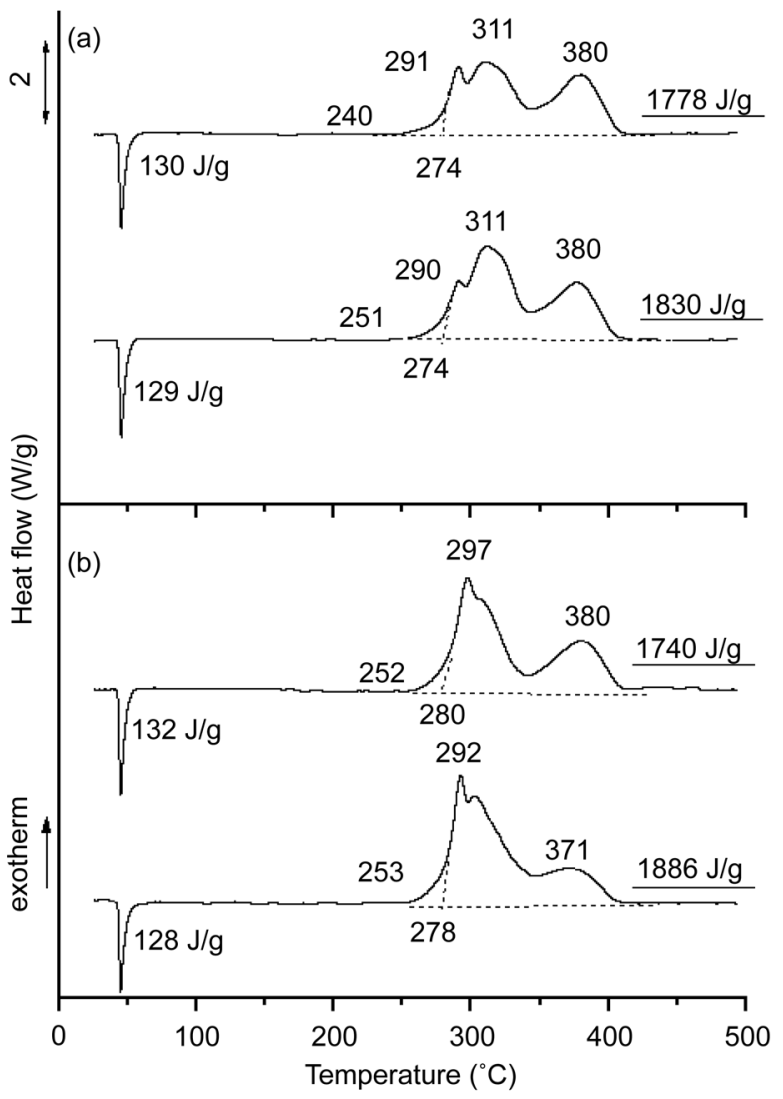

Figure 5. Influence of the addition of a stainless-steel foil on the DSC curve (a) oNP only, (b) the addition of SUS304 foil. 
(a) before
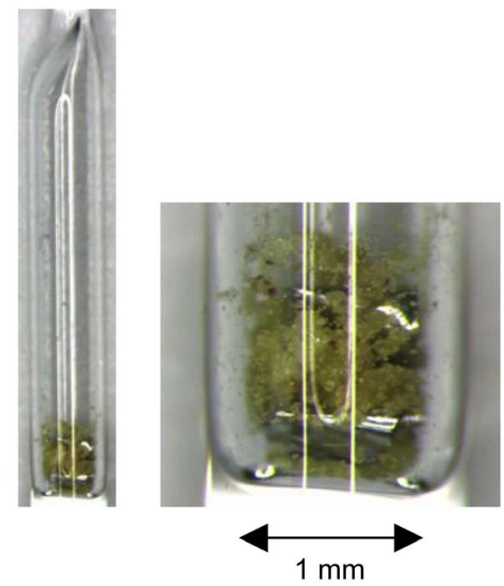

Figure 6. The microscopic photograph of a GC before and after the measurement (addition of SUS304 foil).

(b) after

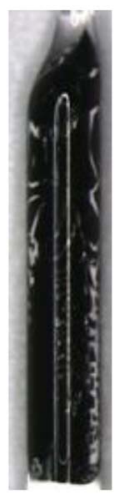

possible to comment on the calorific value associated with this effect, because the influence on energy calibration by the addition of the SUS foil is unknown. It is thought that the change in the peak shape is caused by not only the volatile nature of the sample but also the reaction with the stainless steel. A similar tendency is also confirmed in the case of pNP. On the other hand, although pNT is also volatile at room temperature, the change in the thermal behavior is not confirmed by the addition of the stainless-steel foil. It is supposed that the decrease in $Q_{D S C}$ is caused by the volatility of the sample only in the case of pNT.

In any case, mono-nitrophenol might react with stainless steel. If the acidity of the phenols is involved, the acidity is higher in trinitrophenol. However, there is no difference between the $Q_{D S C}$ obtained with the glass vessels (GC/GA) and the stainless-steel vessel for TNP. Further research is necessary for elucidation of the reason.

\subsection{Substance Containing a Halogen or Sulfur}

When evaluating some substances having particular characteristic structures, such as functional groups containing a halogen or sulfur, the $\mathrm{Q}_{\mathrm{DSC}}$ value obtained in a glass vessel is notably smaller than that obtained in a stainless-steel vessel. It is well known that stainless steel reacts with a halogen, and the results obtained in this study certainly support this fact. For example, the DSC curve of 3-chloroperbenzoic acid (mCPBA) shown in Figure 7 clearly shows that the peak becomes much sharper when a stainless-steel vessel is used. The peak temperature is also shifted into the low temperature range, and takes on a more complex shape at higher temperatures. Plainly, the use of a stainless-steel vessel to evaluate the thermal reactivity of halogen-containing substances is problematic, and thus, is best avoided.

On the other hand, Figure 8 shows the DSC curves of TSC as a notable example of sulfur-containing substances. Furthermore, microphotographs of the vessel taken during the experiment are shown in Figure 9 for the temperatures (A) 


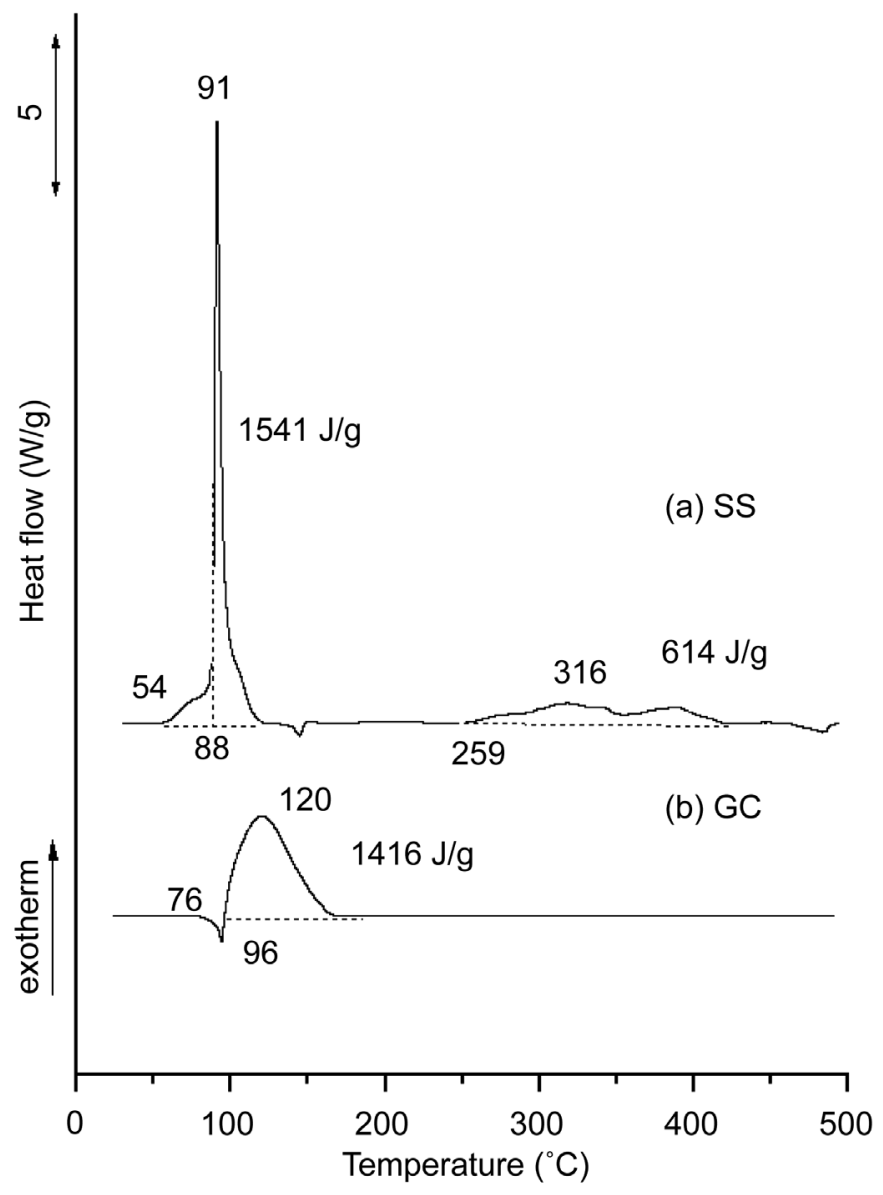

Figure 7. DSC curve for mCPBA (vessel: (a) SS, (b) glass capillary (GC)). The addition of a stainless-steel foil on the DSC curve (a) oNP only, (b) the addition of SUS304 foil.

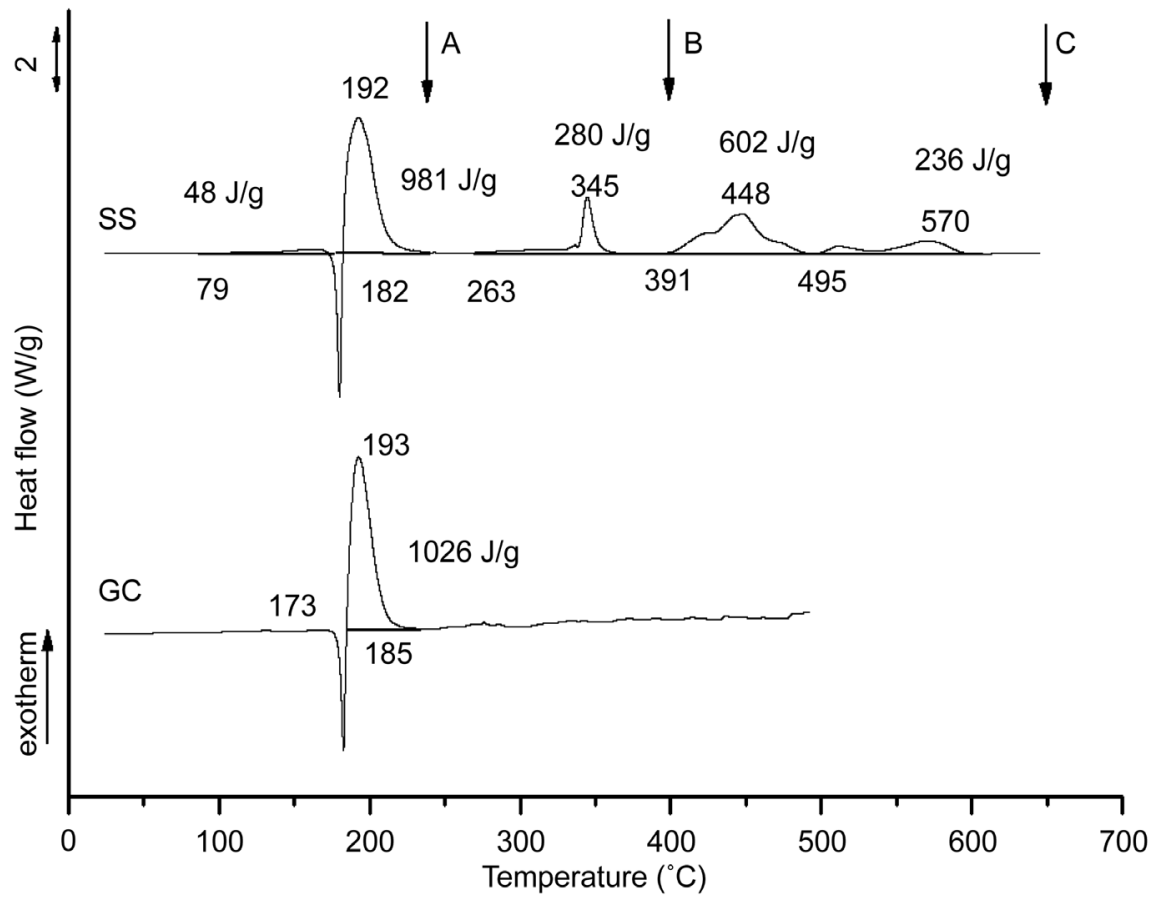

Figure 8. DSC curve for TSC (vessel: (a) SS, (b) glass capillary (GC)). 
240, (B) 400 , and (C) $650^{\circ} \mathrm{C}$ in Figure 5. Figure 10 also shows microphotographs of the glass capillary vessel before and after the DSC measurement. In the glass capillary vessel (GC) experiment, there is a single peak in the DSC curve. After measurement, an orange liquid residue is found. In the stainless-steel vessel, a small amount of corrosion is confirmed at $400^{\circ} \mathrm{C}$, and at $650^{\circ} \mathrm{C}$, there is a notable increase in the surface roughness of the vessel. However, there is no observable change in the vessel surface at $240^{\circ} \mathrm{C}$. Furthermore, an orange liquid residue is confirmed, like the residue observed with a glass capillary vessel (GC). We expect that the same phenomenon occurs in the glass capillary vessel at $240^{\circ} \mathrm{C}$. Thirty-four fragments are detected at temperatures of $240^{\circ} \mathrm{C}$ or greater in

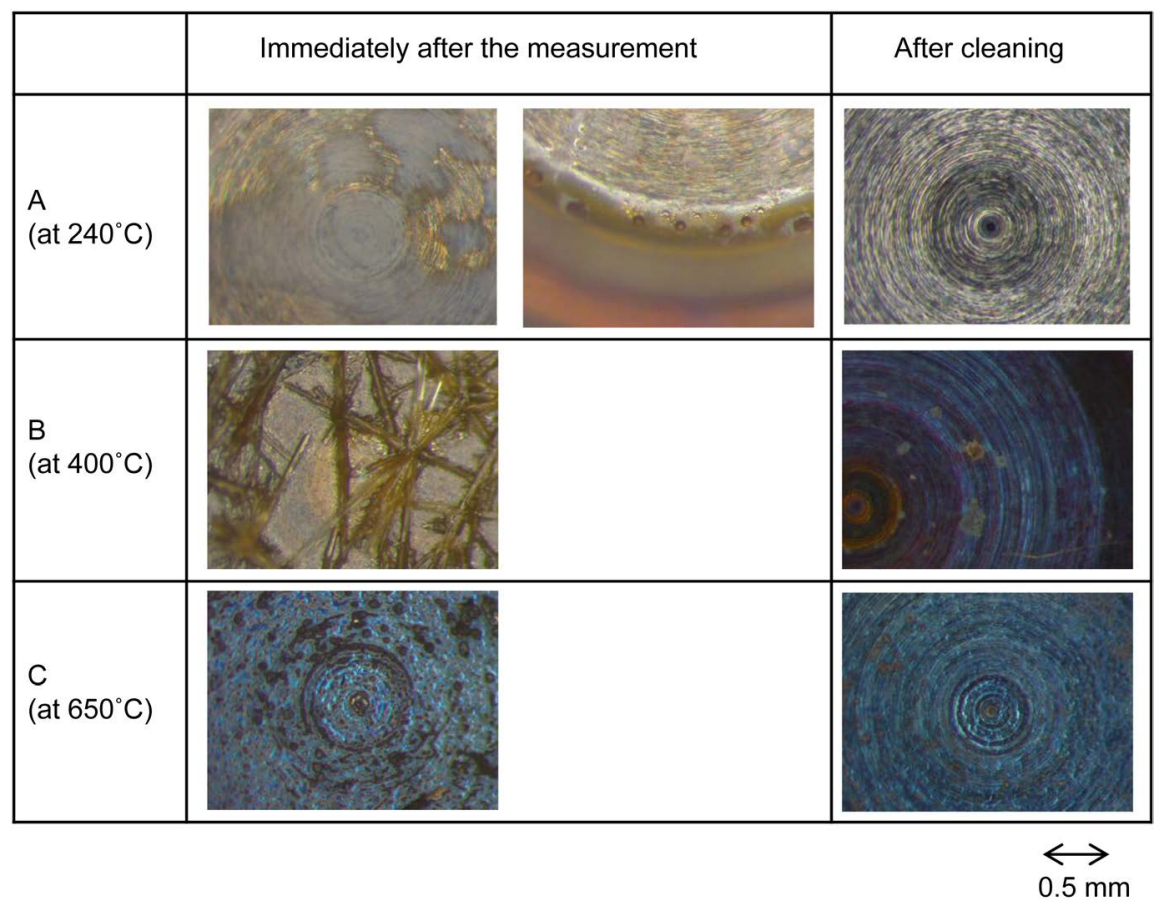

Figure 9. The microscopic photograph of the vessel after the measurement (sample: TSC).

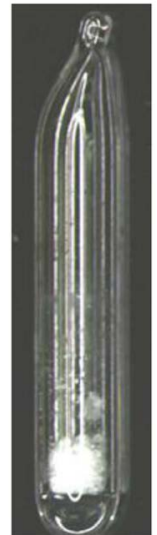

(a) before

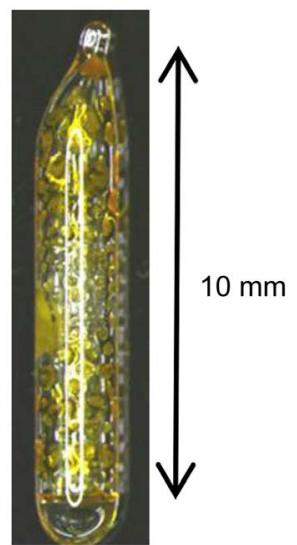

(b) after

Figure 10. The microscopic photograph of the glass capillary (GC) before and after the measurement (sample: TSC). 
the investigation of TG-MS measurement, and the rotten-egg odor of hydrogen sulfide is also evident. In addition, SOx gas is detected in another substance containing sulfur and oxygen in its structure (64 of the fragments). In this way, it is thought that these corrosive gases deteriorate stainless steel in the case of substances containing sulfur. On the other hand, as for substances having the thiosemicarbazide group in their structure, if the molecular weight increases, e.g., for 1-phenyl-3-thiosemicarbazide, the influence on the vessel material diminishes.

\subsection{Substance Containing a Hydrazine Bond}

In the case of a substance containing a hydrazine bond, two types of substances react with the stainless steel: DFH and APH. Here, as for 4-phenylhydrazine, there are differences between the QDsc values obtained with the two types of glass vessels. When pNPH fills a glass capillary vessel, it unavoidably attaches to the wall surface of the container. The sample that is attached to the upper part of the glass vessel is dissolved partly by heating (Figure 11(c)) when the glass capillary vessel is sealed. A black substance adheres to the container in an extreme case, as shown in Figure 11(d), and this sample probably decomposes rather than melting. Adhesion to the wall surface is observed especially in this sample. The glass capillary vessel is observed with a microscope after filling with the sample, and this is not used for the measurement if a black substance is confirmed. Suitable examples are shown in Figure 11(a) and Figure 11(b).

The DSC curve for DFH is presented in Figure 12. The heat behaviors for the stainless-steel vessel and the glass capillary vessel (GC) begin to deviate in the low temperature range, unlike those for TSC. Figure 13 shows a microphotograph of the stainless-steel vessel at $260^{\circ} \mathrm{C}$, where corrosion is evident. The generation of HCN (27 of the fragments) gas is confirmed by TG-MS. On the other hand, the generation of gases that might cause corrosion is not confirmed for

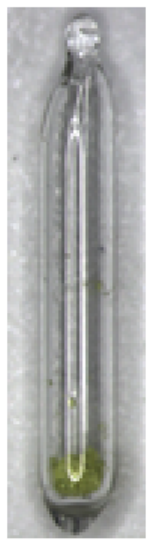

(a) oNP

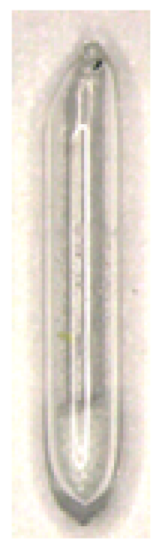

(b) TSC

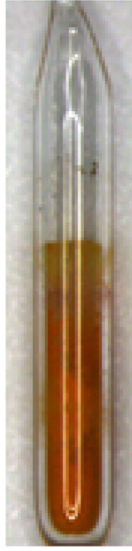

(c) $\mathrm{pNPH}$

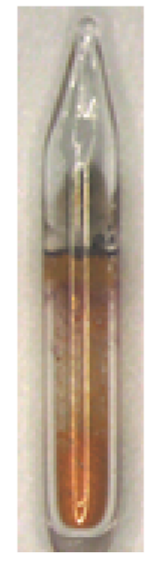

(d) $\mathrm{pNPH}$

Figure 11. The microscopic photograph of the glass capillary vessel before the measurement in various samples (good example: (a), (b), bad example: (d)). 


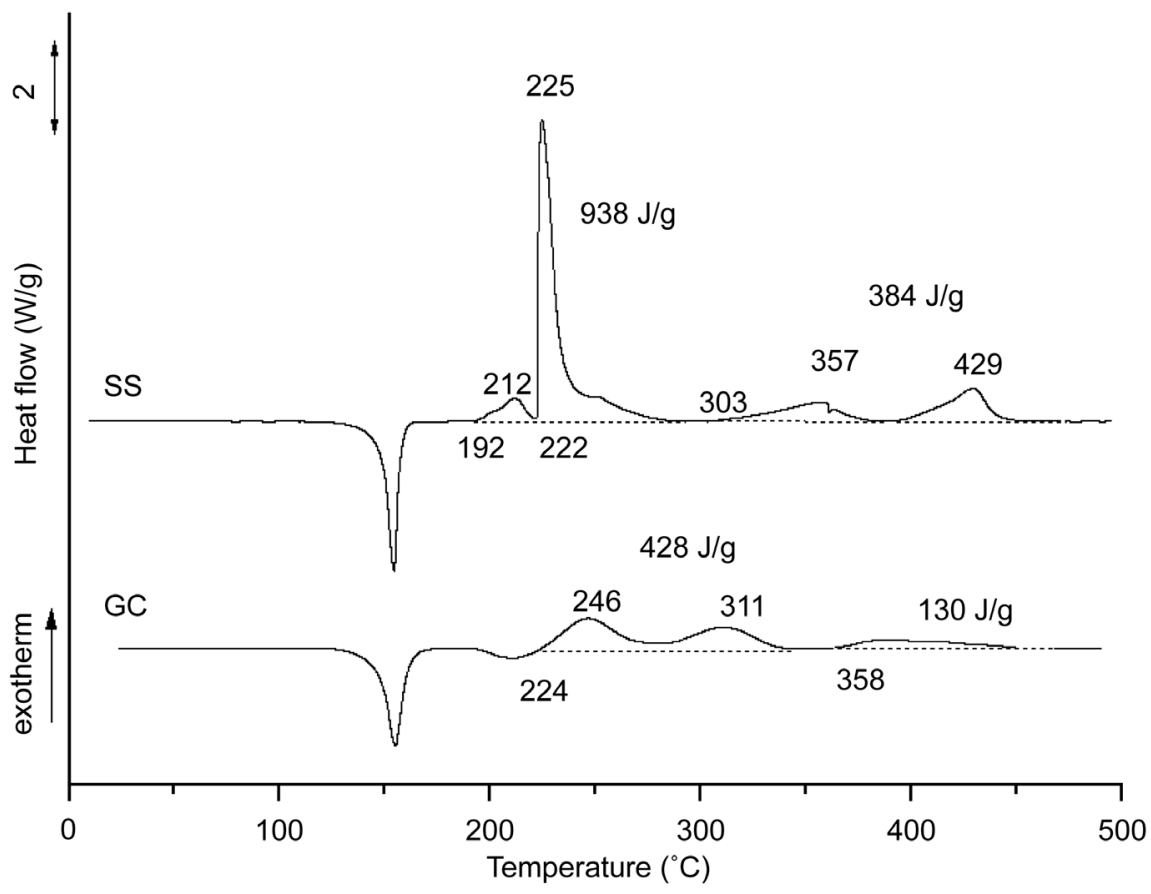

Figure 12. DSC curve for DFH (vessel: SS, glass capillary (GC)).

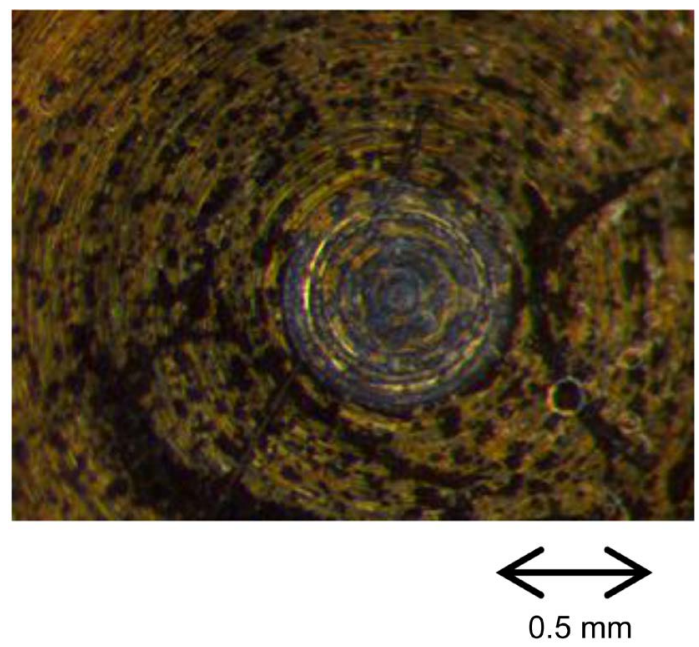

Figure 13. The microscopic photograph of the vessel after the measurement (sample: DFH, vessel: SS).

1-acetyl-phenylhydrazine. The decomposition product, which reacts with stainless steel, may be formed, not in the vapor phase but in the condensation phase. The product in the condensation phase has not yet been investigated. In the future, we will investigate whether there is a particular structural group in substances that react with the stainless-steel vessel.

\subsection{Peroxides and Other Materials}

In peroxides and other materials, there is no significant difference between the $\mathrm{QDSC}_{\mathrm{DS}}$ obtained with a glass vessel and that with a stainless-steel vessel. However, a difference is confirmed in the peak shape, as for TBH. Figure 14 shows the 


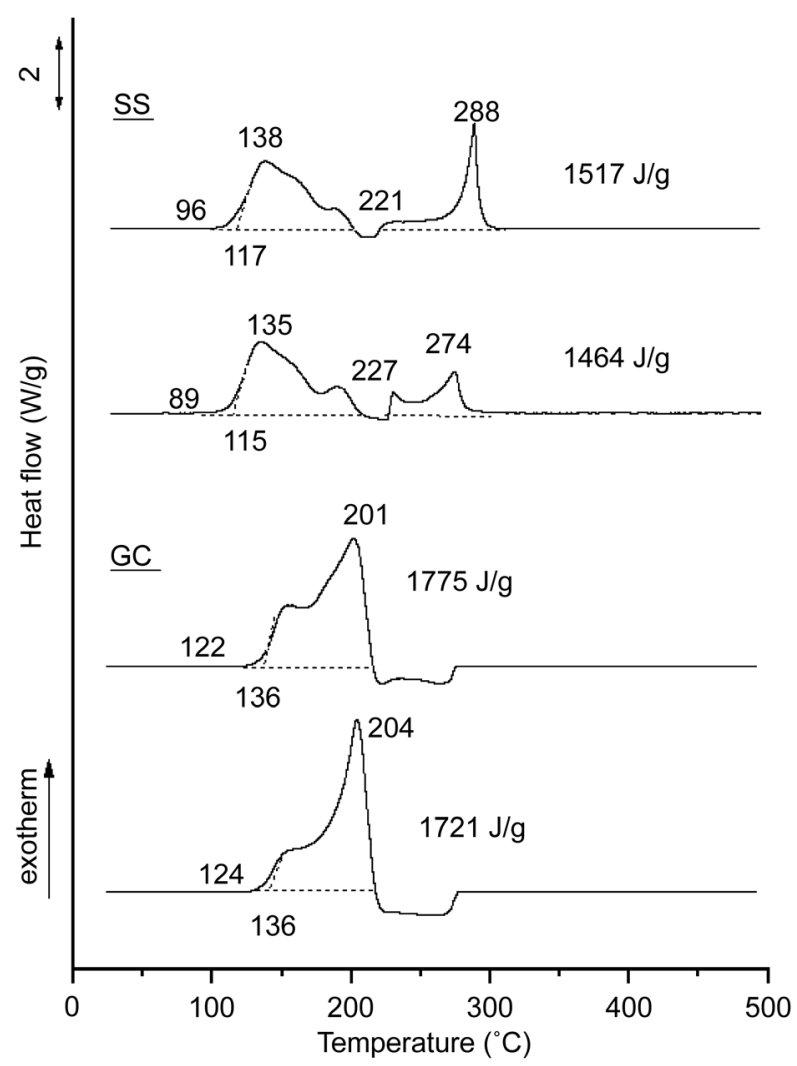

Figure 14. DSC curve for TBH (vessel: SS, glass capillary (GC)).

DSC curve obtained using the glass capillary vessel (GC) and the stainless-steel vessel (SS) with TBH. Here, the peak shapes obtained with the two types of glass vessels (GC and GA) are consistent despite the difference in the sample scale. Reproducibility is achieved for the results with the glass vessel. If the peak shapes are different, the calorific behavior for the different phenomena is evaluated, even if there is no difference in the calorific value. This phenomenon is confirmed only for TBH in this study. TBH is also volatile at room temperature, like oNP and pNT. It is also confirmed that varying the amount of TBH in the vessel affects the peak shape. However, in the case of TBH, the results are found to change in relation to the composition of the lid and body of the stainless-steel vessel. Figure 15 shows the DSC curves obtained with various lid compositions of the stainless-steel vessels. Here, the body composition of the vessel is the same. Figure 16 shows the compositions of the lids shown in Figure 15. It is confirmed that the lid compositions influence the peak shapes and $\mathrm{Q}_{\mathrm{DSC}}$ values. On the other hand, the influence of the body composition on the DSC curve is less than that of the lids. This suggests that the decomposition behavior of TBH is influenced more by a gas-phase reaction, and the generated gas appears to react with stainless steel. In this sample, it is thought that the change in the peak shape is caused not only by the volatility of the sample but also by the reaction with the stainless steel. Further research is needed regarding this phenomenon.

Based on the above results, it is proposed that in all substances containing sulfur or halogen, if thermal evaluation is performed with a stainless-steel vessel, 


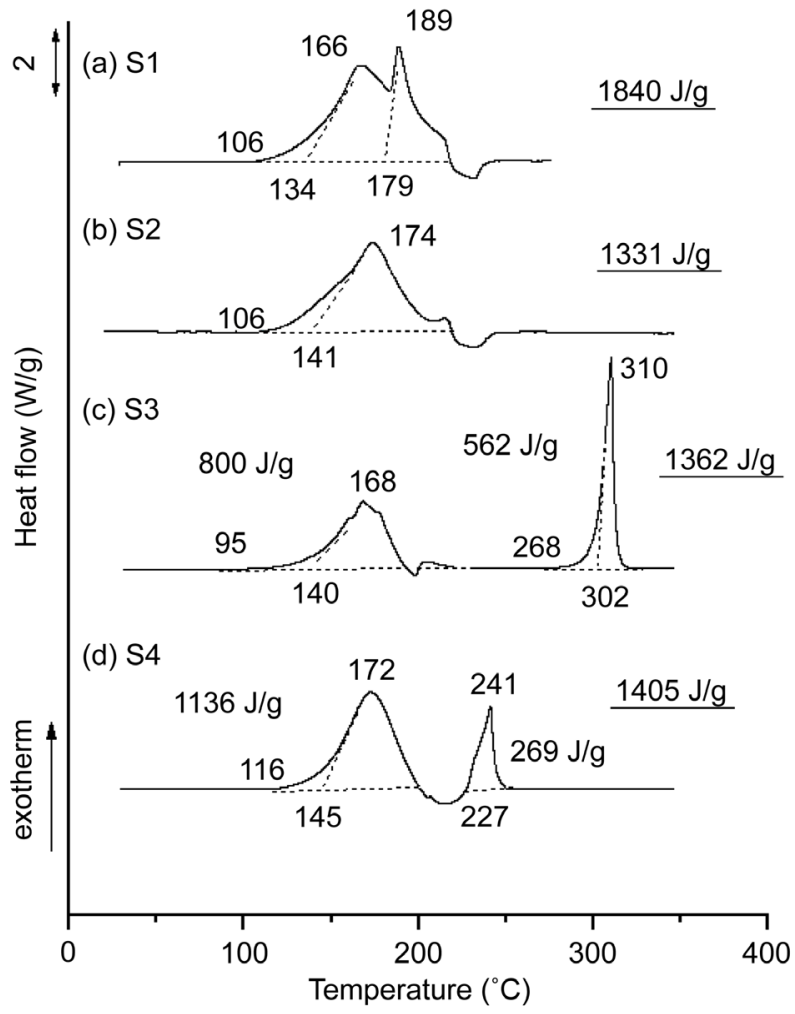

Figure 15. DSC curve for TBH (vessel: stainless-steel vessel with various lid compositions).

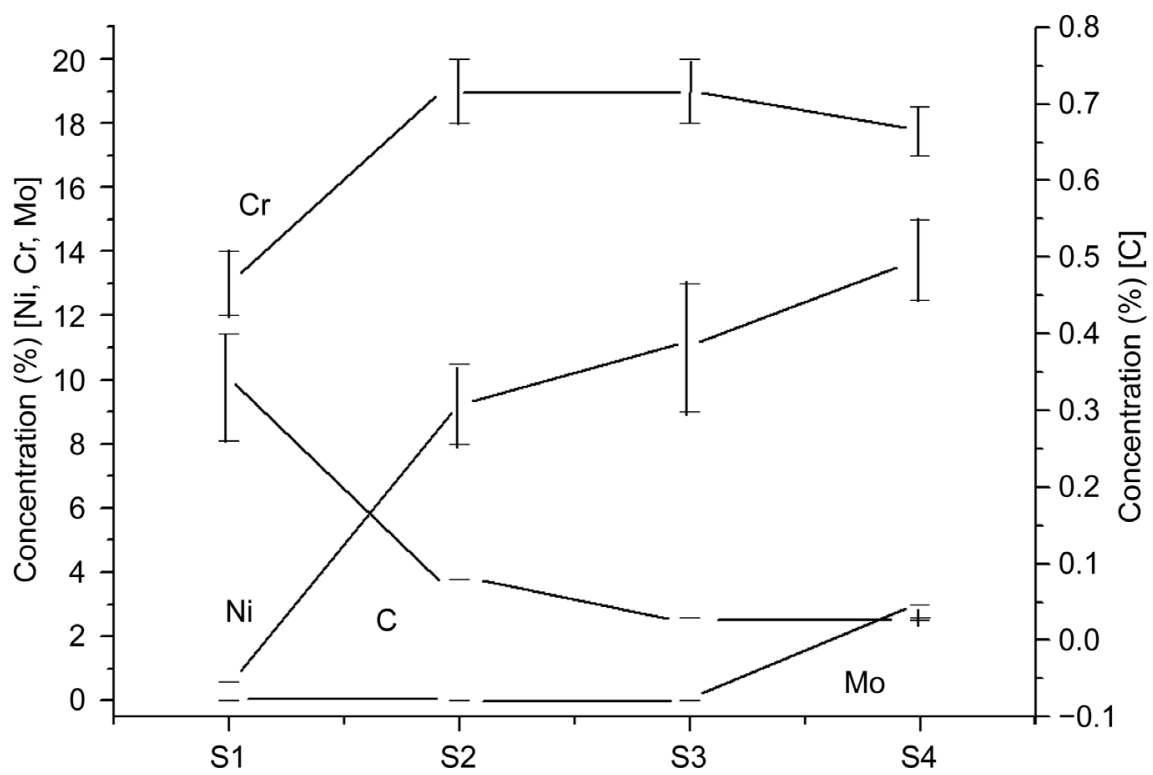

Figure 16. The lid compositions represented in Figure 15.

then $\mathrm{QDSC}_{\mathrm{DS}}$ will be affected by the vessel material. For such substances, a stainless-steel vessel is inappropriate and an inert material should be used.

For other substances, we intend to clarify whether there is a particular structural group in the substance that reacts with stainless steel. We plan to evaluate the $\mathrm{Q}_{\mathrm{DSC}}$ of more materials. 
Where $\mathrm{Q}_{\mathrm{DSC}}$ is affected by the stainless steel, the $\mathrm{Q}_{\mathrm{DSC}}$ value obtained in a glass vessel is smaller than that obtained in a stainless-steel vessel in almost all cases. The thermal hazard is overestimated when a stainless-steel vessel is used; thus, it might be safer to use this in screening tests for explosive chemicals by the United Nations. However, the most suitable vessel materials should be chosen in order to evaluate the true reactivity of a substance. Care should be taken when evaluating, because on the contrary, the glass vessel might also react with the substance being tested.

\section{Conclusions}

The present investigation was conducted to determine whether using a glass or stainless-steel sample container can affect the measured Q Q cal substances. The $\mathrm{Q}_{\mathrm{DSC}}$ obtained with the stainless-steel vessel was thus analyzed with respect to the permissible range of variation based on a report by the ASTM. We drew the following conclusions:

1) The QDsc values obtained for the two types of glass vessels are generally in agreement, despite differences in the sample scale. QDsc values obtained with the glass capillary vessel for the melting points are within the $Q_{D S C}$ tolerance range for the stainless-steel vessel in all cases. The sample vessel materials appear to affect only the decomposition phenomena.

2) In several cases, the QDSC values obtained for the glass capillary vessel are not within the $\mathrm{Q}_{\mathrm{DSC}}$ tolerance range for the stainless-steel vessel. In all substances containing sulfur or halogen, if the thermal evaluation is performed with a stainless-steel vessel, we conjecture that $Q_{D s c}$ is affected by the vessel material.

3) In the case of sulfur-containing substances, it is confirmed that corrosive gases, such as hydrogen sulfide and SOx gas, are generated and might deteriorate the stainless steel.

4) In some cases, the reason why the $Q_{D S C}$ values are affected by the stainless steel is unclear. We will investigate further regarding whether there are structural regularities in such cases.

5) In the case of substances that undergo sublimation, the peak shape and the calorific value obtained by DSC analysis are affected by the amount of sample relative to the volume of the sample vessel. This is attributed to a change in the ratio of the gas-phase reaction to the condensation-layer reaction.

\section{References}

[1] (1999) Recommendations on the Transport of Dangerous Goods, Manual of Tests and Criteria. 3rd Revised Edition, United Nations, New York, Geneva, 27-47.

[2] (2003) Recommendations on the Transport of Dangerous Goods, Manual of Tests and Criteria. 4th Revised Edition, United Nations, New York, Geneva, 201-212.

[3] (2013) Measurement Method of Exothermic Decomposition Energy for Explosive Estimation. Japanese Standards Association, Tokyo.

[4] Berger, A. and Wehrsted, K.D. (2010) Azodicarboxylates: Explosive Properties and DSC Measurements. Journal of Loss Prevention in the Process Industries, 23, 734 739. https://doi.org/10.1016/j.jlp.2010.06.019 
[5] Lu, K.T., Chen, T.C. and Hu, K.H. (2006) Investigation of the Decomposition Reaction and Dust Explosion Characteristics of Crystalline Benzoyl Peroxides. Journal of Hazardous Materials, 161, 246-256. https://doi.org/10.1016/j.jhazmat.2008.03.078

[6] Malow, M. and Wehrstedt, K.D. (2005) Prediction of the Self-Accelerating Decomposition Temperature (SADT) for Liquid Organic Peroxides from Differential Canning Calorimetry (DSC) Measurements. Journal of Hazardous Materials, 120, 2124. https://doi.org/10.1016/j.jhazmat.2004.12.040

[7] Malow, M., Wehrstedt, K.D. and Neuenfeld, S. (2007) On the Explosive Properties of 1H-Benzotriazole and 1H-1,2,3-Triazole. Tetrahedron Letters, 48, 1233-1235. https://doi.org/10.1016/j.tetlet.2006.12.046

[8] Hsueha, K.-H., Chenb, W.-C., Chenc, W.-T. and Shub, C.-M. (2016) Thermal Decomposition Analysis of 1,1-Bis(tert-butylperoxy)cyclohexane with Sulfuric Acid Contaminants. Journal of Loss Prevention in the Process Industries, 40, 357-364. https://doi.org/10.1016/j.jlp.2016.01.018

[9] Yi, J.H., Zhao, F.Q., Xu, S.Y., Zhang, L.Y., Gao, H.X. and Hu, R.Z. (2009) Effects of Pressure and TEGDN Content on Decomposition Reaction Mechanism and Kinetics of DB Gun Propellant Containing the Mixed Ester of TEGDN and NG. Journal of Hazardous Materials, 165, 853-859. https://doi.org/10.1016/j.jhazmat.2008.10.107

[10] Nair, U.R., Gore, G.M., Sivabalan, R., Pawar, S.J., Asthana, S.N. and Venugopalan, S. (2007) Preparation and Thermal Studies on Tetranitrodibenzotetraazapentalene (TACOT): A Thermally Stable High Explosive. Journal of Hazardous Materials, 143, 500-505. https://doi.org/10.1016/j.jhazmat.2006.09.065

[11] Gańczyk, K., Zygmunt, A. and Gołofit, T. (2016) Thermal Properties of TEX Decomposition or Sublimation. Journal of Thermal Analysis and Calorimetry, 125, 967-975. https://doi.org/10.1007/s10973-016-5476-9

[12] Gunawana, R. and Zhangb, D. (2009) Thermal Stability and Kinetics of Decomposition of Ammonium Nitrate in the Presence of Pyrite. Journal of Hazardous Materials, 165, 751-758. https://doi.org/10.1016/j.jhazmat.2008.10.054

[13] Chervin, S. and Bodman, G.T. (2002) Phenomenon of Autocatalysis in Decomposition of Energetic Chemicals. Thermochimica Acta, 392-393, 371-383. https://doi.org/10.1016/S0040-6031(02)00122-3

[14] Akiyoshi, M., Okada, K., Usuba, S. and Matsunaga, T. (2011) Effects of Various Vessel Materials on Exothermic Decomposition Energy Measurements. Thermochimica Acta, 515, 6-12. https://doi.org/10.1016/j.tca.2010.12.009

[15] ASTM E537-07 (2007) Standard Test Method for the Thermal Stability of Chemicals by Differential Scanning Calorimetry.

[16] ASTM Research Report RR: E27-1003 (2002) Interlaboratory Test Study for E537 Assessing the Thermal Stability of Chemicals by Methods of Thermal Analysis.

[17] As for All Graphs, the Exhibition with the Database Is Planned. 
Submit or recommend next manuscript to SCIRP and we will provide best service for you:

Accepting pre-submission inquiries through Email, Facebook, LinkedIn, Twitter, etc. A wide selection of journals (inclusive of 9 subjects, more than 200 journals)

Providing 24-hour high-quality service

User-friendly online submission system

Fair and swift peer-review system

Efficient typesetting and proofreading procedure

Display of the result of downloads and visits, as well as the number of cited articles Maximum dissemination of your research work

Submit your manuscript at: http://papersubmission.scirp.org/

Or contact ajac@scirp.org 